\title{
Asthma and obesity: does weight loss improve asthma control? a systematic review
}

This article was published in the following Dove Press journal:

Journal of Asthma and Allergy

6 June 2012

Number of times this article has been viewed

\section{Caroline Trunk-Black Juel' \\ Zarqa Ali ${ }^{1}$ \\ Lisbeth Nilas² \\ Charlotte Suppli Ulrik'}

'Respiratory Section, Internal Medicine Unit, 'Department of Obstetrics and Gynaecology, Hvidovre Hospital and University of Copenhagen, Hvidovre, Denmark
Correspondence: Charlotte Suppli Ulrik Respiratory Section 253, Internal Medicine Unit, Hvidovre Hospital, DK-2650, Hvidovre, Denmark Email csulrik@dadlnet.dk
Aim and methods: Obesity is a major health problem, and obesity is associated with a high incidence of asthma and poor asthma control. The aim of the present paper is to systematically review the current knowledge of the effect on overall asthma control of weight reduction in overweight and obese adults with asthma.

Results: Weight loss in obese individuals with doctor-diagnosed asthma is associated with a $48 \%-100 \%$ remission of asthma symptoms and use of asthma medication. Published studies, furthermore, reveal that weight loss in obese asthmatics improves asthma control, and that especially surgically induced weight loss results in significant improvements in asthma severity, use of asthma medication, dyspnoea, exercise tolerance, and acute exacerbations, including hospitalizations due to asthma. Furthermore, weight loss in obese asthmatics is associated with improvements in level of lung function and airway responsiveness to inhaled methacholine, whereas no significant improvements have been observed in exhaled nitric oxide or other markers of eosinophilic airway inflammation.

Conclusion: Overweight and obese adults with asthma experience a high symptomatic remission rate and significant improvements in asthma control, including objective measures of disease activity, after weight loss. Although these positive effects of weight loss on asthmarelated health outcomes seem not to be accompanied by remission or improvements in markers of eosinophilic airway inflammation, it has potentially important implications for the future burden of asthma.

Keywords: asthma, weight loss, diet, bariatric surgery, asthma control

\section{Introduction}

The prevalence of obesity has increased dramatically over recent decades, and obesity is recognized as an important risk factor for a diagnosis of asthma. ${ }^{1}$ Furthermore, evidence from recent years suggests a probable shared genetic basis for obesity and asthma. ${ }^{2}$ More recently, obesity has also been recognized as a potential risk factor for more severe asthma. ${ }^{3-5}$ Obesity may therefore be a potentially modifiable risk factor for asthma, possibly not least with regard to the more severe asthma. If excess weight not only leads to the development of asthma, but also has a negative impact on the clinical manifestations of asthma, including symptoms and response to therapy, weight loss may be expected to have the opposite effect or at least to improve the clinical status of individuals suffering from asthma.

Overall asthma control, in contrast to, eg, symptom control, is the aim of asthma management. ${ }^{6}$ Asthma control is assessed on the basis of a combination of the following items: exacerbations, frequency and severity of day-time and night-time symptoms, use of 
rescue medication, limitations and level of daytime activities, variability of lung function ie, forced expiratory volume in 1 second $\left(\mathrm{FEV}_{1}\right)$, and diurnal variability in peak flow. ${ }^{6}$

The aim of the present paper has been to review the current knowledge of the effect of weight reduction on overall asthma control in obese individuals suffering from asthma.

\section{Methods}

A series of systematic searches were carried out, last updated March 2012, using the database PubMed. The search strategy was intended to be broad in order to maximize the capture of citations for peer-reviewed publications relevant to asthma, obesity, and asthma control. The PubMed searches were carried out using the following algorithm of MeSH terms: asthma, asthma-like symptoms, asthma control, asthma management, asthma severity, airway hyperresponsiveness including bariatric surgery, diet, weight loss, obesity, and overweight. The searches were repeated with these terms in combination with pathogenesis, airway inflammation, therapy, and epidemiology. All identified publications were evaluated, and all papers identified reporting measures of asthma control (including symptoms, use of asthma medication, level of lung function, quality of life, and markers of airway inflammation) following weight loss related to both nonsurgical and surgical intervention were included in the present systematic review. The citation pool was further supplemented from manual assessment of the reference lists accompanying other systematic reviews of aspects related to asthma in obese individuals and from other publications identified as being relevant for further review. In keeping with the already described method, papers were included in the present review provided they reported measures of asthma control following weight loss related to both surgical and nonsurgical interventions.

\section{Nonsurgical weight loss and asthma control}

In a pivotal clinical trial, Stenius-Aarniala et $\mathrm{al}^{7}$ recruited 38 obese asthmatics (BMI 30 to 42) into an open, randomized parallel group study investigating the effects of a supervised weight reduction program, which included an eight-week, very low-energy diet, on lung function, symptoms, and health status. At the end of the intervention period, the participants in the treatment group had lost a mean $14.5 \%$ of their pretreatment weight (mean $14.2 \mathrm{~kg}$ ), and $0.3 \%$ for the controls (mean $0.3 \mathrm{~kg}$ ). After the eight-week dieting period, significant improvement was observed in individuals in the intervention group in $\mathrm{FEV}_{1}$, forced vital capacity (FVC), dyspnoea, use of rescue medication, and number of exacerbations, compared to the controls. The study by Stenius-Aarniala, ${ }^{7}$ therefore, indicates that weight loss in obese patients with asthma leads to improved asthma control. In a further study from the same group, Hakala et $\mathrm{al}^{8}$ measured peak-flow (PEF) variability, morning PEF and $\mathrm{FEV}_{1}$, mid-expiratory flow, airway resistance $\left(\mathrm{R}_{\mathrm{aw}}\right)$, and functional residual capacity in 14 obese patients with asthma before and after an eight-week, very low calorie diet (mean weight loss $13.7 \mathrm{~kg}$ ). Based on the reported observations, the authors suggested that obese patients with asthma might benefit from weight loss by an improvement in pulmonary mechanics and better control of airway obstruction.

Obese individuals often do not adhere to low-calorie diets, and Johnson et $\mathrm{al}^{9}$ therefore designed a study to assess if overweight asthma patients might adhere to an alternateday calorie restriction dietary regimen, and furthermore to investigate the effects of the diet on symptoms, lung function, and inflammation. Nine out of ten subjects adhered to the diet for the eight-week study period, and mean weight loss was $8 \%$ of pre-study weight. The study revealed an improvement in asthma symptoms, quality of life, PEF, and markers of inflammation (including serum tumor necrosis factor- $\alpha$ ), and oxidative stress (including 8-isoprostane and nitrotyrosine), whereas spirometry was unaffected by alternate-day calorie restriction. The observations in this very small study may suggest that alternate-day calorie restriction has a rapid beneficial effect on the underlying disease process in obese patients with asthma.

In 2010, Bafadhel et a ${ }^{10}$ examined 151 adults fulfilling the American Thoracic Society criteria ${ }^{6}$ for severe asthma in a one-year observational study. BMI and fat mass index correlated, and $75 \%$ of the patients included were overweight or obese. After twelve months, $23 \%$ of the patients had lost weight, and a significant correlation was observed between weight loss and increased $\mathrm{FEV}_{1}$, whereas no significant association was found between weight change and self-reported asthma control and exacerbations.

In an uncontrolled study, Aaron et $\mathrm{al}^{11}$ included 58 obese women, of whom 24 had a history of physician-diagnosed asthma, in a program consisting of a $900 \mathrm{kcal}$ per day diet for six to twelve weeks and regular exercise, in a study investigating the effect of weight loss on respiratory function and airway responsiveness. The mean weight loss was $17.4 \%$ of baseline weight, and improvements were observed in $\mathrm{FEV}_{1}, \mathrm{FVC}$, and total lung capacity. By contrast, no significant improvement was observed in airway responsiveness (defined as airway responsiveness to inhaled methacholine), either in the entire group or in the subgroup of women with a history of physician-diagnosed asthma. This suggests that 
weight loss improves respiratory function independently of the severity of airway responsiveness, rather than by improving asthma per se.

Haselkorn et $\mathrm{al}^{12}$ studies, based on data from the epidemiology and natural history of asthma: Outcomes and Treatment Regimens (TENOR) study, the effect of weight change over a twelve-month period on asthma control in patients with severe or difficult-to-treat asthma. Compared to patients who maintained their baseline weight or lost weight, asthma patients with a weight gain of $2.27 \mathrm{~kg}$ reported poorer asthma control, worse quality of life, and a greater number of steroid bursts. This study, therefore, showed that weight gain is associated with worse asthma-related health outcomes, and, in line with this, that strategies to prevent weight gain in patients with more severe asthma may lead to improved asthma control.

\section{Attitudes and counseling related to weight loss}

Ford et $\mathrm{a}^{13}$ have, based on data from the Behavioural Risk Factor Surveillance System, reported that $27.3 \%$ out of 13,953 participants with current asthma had a BMI of $\geq 30$, and that $72.9 \%$ of the obese participants with asthma reported trying to lose weight. Furthermore, $82.9 \%$ of obese participants receiving weight-loss advice reported trying to lose weight, compared to $63.8 \%$ among obese participants who had not received such advice. This study, therefore, illustrates, although so far not supported by other studies, the important role for health care professionals in educating their patients with asthma about the importance of weight control, and in assisting and supporting their overweight and obese patients with asthma in setting achievable weight goals.

\section{Bariatric surgery, weight loss, and asthma control}

The first study investigating the effect of surgically induced weight loss on asthma was published by Macgregor and Greenberg $^{14}$ in 1993 . Forty morbidly obese patients with asthma who had gastric restrictive surgery more than two years earlier (mean BMI 46 and 30, respectively) were examined, and they found that $48 \%$ had complete asthma remission, defined as no symptoms and no use of asthma medication; overall, $90 \%$ of the patients experienced improvement in asthma symptoms. Objective assessment of airway function was not included in the study. In keeping with this, Murr et $\mathrm{al}^{15}$ reported a $100 \%$ remission rate after an average 30 months after bariatric surgery in a very small group of morbidly obese asthmatics $(n=6)$ older than 50 years, although it should be taken into account that asthma status was not the main outcome variable of interest.

In an Australian study published in 1999, Dixon et $\mathrm{al}^{16}$ had the opportunity to investigate the effects over twelve months of weight loss on asthma in 32 patients having the laparoscopic adjustable gastric banding (LAGB) procedure for the management of morbidly obesity (mean baseline BMI 46, and BMI 33 at follow-up). Asthma was defined as a history of physician-diagnosed asthma with no further objective assessment prior to inclusion in the study, and asthma severity and its impact on daily life was assessed by questionnaire. At the twelve-month follow-up, significant improvement was observed in all asthma scores, including medication needs, hospitalizations, and exercise tolerance, and eleven patients reported no longer having asthma symptoms. This relatively early study, therefore, suggests that bariatric surgery in morbidly obese patients with asthma leads not only to weight loss, but also to significant improvement in asthma-related health outcomes, although at least some of the positive effects may be explained primarily by the significant weight loss. In line with this, a one-year study from Latin America of 30 morbidly obese patients who underwent vertical banded gastroplasty showed significant improvements compared to baseline in $\mathrm{FEV}_{1}$ and $\mathrm{FVC}$, and an unchanged $\mathrm{FEV}_{1} / \mathrm{FVC}$ ratio at follow-up (mean BMI 44 and 32, respectively). ${ }^{17}$ A year later, Spivak et $\mathrm{al}^{18}$ reported from a follow-up study of 500 morbidly obese patients, of whom only eleven reported asthma at baseline (mean preoperative weight $123 \mathrm{~kg}$ ), that $82 \%$ of the subjects preoperatively reporting asthma no longer had symptoms of asthma at the time of follow-up 36 months after LAGB, which is in keeping with observations reported by Dhabuwala et al, ${ }^{19}$ O'Brien et al, ${ }^{20}$ and Brancatisano et al. ${ }^{21}$ However, as in a number of the available studies, no objective assessment of airway function was done, and the assessment of illness status, including asthma, was based solely on symptoms and/or prescribed medications.

In a relatively small one-year prospective study, Maniscalco et $\mathrm{al}^{22}$ compared twelve obese asthmatic females who had LAGB (mean BMI 45 and 35, respectively) and ten non-operated obese asthmatic females (mean BMI 44, no weight change) with regard to self-reported asthma control, lung function, and exhaled nitric oxide (FeNO). Improvements were observed in asthma control, especially shortness of breath and use of rescue medication, and lung function in the LAGB-group, whereas FeNO remained unchanged in both groups. FeNO is closely associated with eosinophilic airway inflammation, ${ }^{23}$ and the latter observation, therefore, 
suggests that the overall improvement in asthma status in the LAGB group is not due to remission of the airway inflammation typically seen in patients with asthma.

In a very recent study, Dixon et $\mathrm{al}^{24}$ studied 23 asthmatic and 21 non-asthmatic patients (mean BMI 51 and 38 , respectively) undergoing bariatric surgery; at baseline, patients with asthma had lower $\mathrm{FEV}_{1}$ and FVC than the non-asthmatic patients. Twelve months after surgery, patients with asthma experienced significant improvements in asthma control, asthma-related quality of life, $\mathrm{FEV}_{1}$, and FVC; and, furthermore, a significant improvement was observed in airway responsiveness to methacholine, whereas no significant changes were observed in most inflammatory markers, including percentage of eosinophils in bronchoalveolar lavage fluid. The response to direct airway-challenge testing partly reflects airway caliber; ${ }^{25}$ the observed improvement in methacholine responsiveness might be explained by changes in airway mechanics, and might not be due to a decrease in airway inflammation.

\section{Weight loss and use of respiratory medication}

Obesity is not only associated with increased morbidity rates, but also with increased pharmaceutical costs. Narbro et $\mathrm{al}^{26}$ studied medication changes over six years in 510 surgically and 455 conventionally treated patients from the Swedish Obese Subjects intervention study, and reported that, compared to baseline, asthma medication costs were lower for the surgically treated group of patients. These observations have been confirmed in a recent study by Sikka et $\mathrm{al}^{27}$ of respiratory prescription drug claims in 64 asthma patients over a two-year period (one year before to one year after bariatric surgery): it showed a $49 \%$ decrease in respiratory medication prescription fills.

Reddy et $\mathrm{al}^{28}$ studied the effects of bariatric surgery on asthma severity, defined as intensity of asthma therapy, in 2,562 patients reporting use of asthma medication at baseline. Among the 257 asthma patients who participated in a one-year follow-up survey, 13 of 28 patients had been weaned from long-term oral corticosteroid therapy; and the use of inhaled corticosteroids decreased from approximately $50 \%$ to $30 \%$, suggesting that bariatric surgery decreases the medication requirements for control of asthma symptoms. Objective measures of asthma control were not included in the study. These findings are further supported by a study by Sultan et $\mathrm{al}^{29}$ looking at the outcome of bariatric surgery in individuals with a BMI $<35$, as well as by a study by Ahroni et al. ${ }^{30}$

\section{Discussion}

In general, all studies published so far show that weight loss in obese asthmatics improves asthma control; and, furthermore, possibly, especially since surgically induced weight loss results in significant improvements in asthma severity, use of asthma medication, dyspnoea, exercise tolerance, and acute exacerbations of asthma, including hospitalizations due to asthma. ${ }^{7,8,10}$

Studies have also shown that weight loss in obese asthmatics is associated with improvements in level of lung function and airway responsiveness to inhaled methacholine, whereas no significant improvements have been observed in exhaled nitric oxide or other markers of eosinophilic airway inflammation. ${ }^{12,22,24}$ Taken together, these observations therefore indicate that objective markers of asthmatic airway inflammation are not improved to an extent comparable to the improvements observed in symptoms and lung function. It is therefore probable that weight loss induced improvements in asthma control - defined as symptoms, level of lung function, and use of medication - occur due to a reduction in mass loading on the respiratory symptoms rather than improvements in asthma per se. This is further supported by the reported high rate of asthma remission observed after weight loss, which is in contrast to the findings in, on average, normalweight adults with asthma. ${ }^{31}$ However, although the available evidence clearly suggests a direct causality between being overweight and having asthma, meaning that an overweight or obese person is more likely to develop asthma symptoms compared to a normal-weight person who is otherwise identical, ${ }^{32}$ asthma in the overweight or obese patients may in fact be asthma-like symptoms caused by changes in lung mechanics instead of being caused by asthmatic airway inflammation. ${ }^{33}$ Another possible explanation may be that obese patients with asthma represent a distinct asthma phenotype, an explanation supported by recent observations reported by Scott et al. ${ }^{34}$ These showed that, compared to non-obese asthmatics, obese asthmatics had an increase in neutrophilic airway inflammation, whereas no significant difference in the sputum eosinophil percentage was found between obese and non-obese patients. The latter finding may also explain the suboptimal response to conventional asthma therapy often observed in obese patients with asthma. ${ }^{5}$ Furthermore, Deesomchok et $\mathrm{al}^{35}$ have recently reported similar airway responsiveness, assessed by high-dose methacholine challenge tests, in obese and normal-weight asthmatics, in spite of differences in baseline lung volumes. In line with this, Lessard et $\mathrm{al}^{36}$ reported poorer asthma control, assessed by the Asthma Control Questionnaire, ${ }^{37}$ and more activity limitations, dyspnea, and wheezing in obese compared to 
non-obese patients, although no significant differences were observed in night-time awakenings due to asthma, early morning symptoms, or use of reliever medication. These studies, therefore, further support the notion of a very complex association between obesity and asthma.

In conclusion, overweight and obese individuals with asthma experience a high symptomatic remission rate and significant improvements in asthma control, as assessed by symptoms, use of medication, lung function, and hospitalizations, after weight loss. Although these positive effects of weight loss on asthma-related health outcomes seem not to be accompanied by remission or improvements in airway inflammation, they have important implications not only at the individual level, but also with regard to the overall burden of asthma. Very interestingly, all papers identified for this study reported some positive effect of weight loss on asthma control. Future studies, it is hoped, will increase our knowledge of the complex interaction between obesity and asthma, and perhaps define a distinct obese-asthma phenotype, providing us with the measures to improve the overall health status of overweight or obese patients presenting with asthma symptoms, not least with the use of targeted treatment strategies.

\section{Disclosure}

The authors report no conflicts of interest in this work.

\section{References}

1. Camargo CA Jr, Weiss ST, Zhang S, Willett WC, Speizer FE. Prospective study of body mass index, weight change, and risk of adult-onset asthma in women. Arch Intern Med. 1999;159: 2582-2588.

2. Beuther DA, Weiss ST, Sutherland ER. Obesity and asthma. Am J Respir Crit Care Med. 2006;174:112-119.

3. De Marco R, Marcon A, Jarvis D, et al. Prognostic factors of asthma severity: a 9-year international prospective cohort study. J Allergy Clin Immunol. 2006;117:1249-1256.

4. Varraso R, Siroux V, Maccario J, et al. Asthma severity is associated with body mass index and early menarche in women. Am J Respir Crit Care Med. 2005;171:334-339.

5. Lugogo NL, Kraft M, Dixon AE. Does obesity produce a distinct asthma phenotype? J Appl Physiol. 2010;108:729-734.

6. Global Initiative for Asthma (GINA). Global Strategy for Asthma Management and Prevention, updated December 2011. Available from http://www.ginasthma.org/. Accessed on March 10, 2012.

7. Stenius-Aarniala B, Poussa T, Kvarnström J, et al. Immediate and long term effects of weight reduction in obese people with asthma. BMJ. 2000;320:827-832.

8. Hakala K, Stenius-Aarniala B, Sovijärvi A. Effects of weight loss on peak flow variability, airways obstruction, and lung volumes in obese patients with asthma. Chest. 2000;118:1315-1321.

9. Johnson JB, Summer W, Cutler RG, et al. Alternate day calorie restriction improves clinical findings and reduces markers of oxidative stress and inflammation in overweight adults with moderate asthma. Free Radic Biol Med. 2007;42(1):665-674.

10. Bafadhel M, Singapuri A, Terry S, et al. Body mass and fat mass in refractory asthma: an observational 1 year follow-up study. J Allergy. 2010:Article ID 251758.
11. Aaron SD, Fergusson D, Dent R, Chen Y, Vandemheen KL, Dales RE. Effect of weight reduction on respiratory function and airway reactivity in obese women. Chest. 2004;125:2046-2052.

12. Haselkorn T, Fish JE, Chipps BE, Miller DP, Chen H, Weiss ST. Effect of weight change on asthma-related health outcomes on patients with severe or difficult-to-treat asthma. Respir Med. 2009;103: 274-283.

13. Ford ES, Mannino DM, Redd SC, Mokdad AH, Galuska DA, Serdula MK. Weight-loss practices and asthma: findings from the behavioural risk factor surveillance system. Obes Res. 2003;11:81-86.

14. Macgregor AMC, Greenberg RA. Effect of surgically induced weight loss on asthma in the morbidly obese. Obes Surg. 1993;3:15-21.

15. Murr MM, Siadati MR, Sarr MG. Results of bariatric surgery for morbid obesity in patients older than 50 years. Obes Surg. 1995;5: 399-402.

16. Dixon JB, Chapman L, O'Brien P. Marked Improvement in asthma after lap-band surgery for morbid obesity. Obes Surg. 1999;9:385-389.

17. Davila-Cervantes A, Dominguez-Cherit G, Borunda D, et al. Impact of surgically-induced weight loss on respiratory function: a prospective analysis. Obes Surg. 2004;14:1389-1392.

18. Spivak H, Hewitt MF, Onn A, Half EE. Weight loss and improvement of obesity-related illness in 500 US patients following laparoscopic adjustable gastric banding procedure. Am J Surg. 2005;189: $27-32$.

19. Dhabuwala A, Cannan RJ, Stubbs RS, Obst D. Improvement in co-morbidities following weight loss from gastric bypass surgery. Obes Surg. 2000;10:428-435.

20. O'Brien PE, Dixon JB, Brown W, et al. The laparoscopic adjustable gastric band (Lap-Band $\left.{ }^{\circledR}\right)$ : A prospective study of medium-term effects on weight, health and quality of life. Obes Surg. 2002;12: 652-660.

21. Brancatisano A, Waahlroos S, Brancatisano R. Improvement in comorbid illness after placement of the Swedish Adjustable Gastric Band. Surg Obes Relat Dis. 2008;4:S39-S46.

22. Maniscalco M, Zedda A, Faraone S, et al. Weight loss and asthma control in severely obese asthmatic females. Respir Med. 2008;102: $102-108$.

23. Smith AD, Cowan JO, Brassett KP, Herbison GP, Taylor DR. Use of exhaled nitric oxide measurements to guide treatment in chronic asthma. N Engl J Med. 2005;352:2163-2173.

24. Dixon AE, Pratley RE, Forgione PM, et al. Effects of obesity and bariatric surgery on airway hyperresponsiveness, asthma control, and inflammation. JAllergy Clin Immunol. 2011;128:508-515.

25. Ulrik CS. Bronchial responsiveness to inhaled histamine in both adults with intrinsic and extrinsic asthma: the importance of prechallenge $\mathrm{FEV}_{1}$. J Allergy Clin Immunol. 1993;91:120-126.

26. Narbro K, Ågren G, Jonsson E, Näslund I, Sjöström L, Peltonen M. Pharmaceutical costs in obese individuals. Arch Intern Med. 2002;162: 2061-2069.

27. Sikka N, Wegienka G, Havstad S, Genaw J, Carlin AM, Zoratti E. Respiratory medication prescriptions before and after bariatric surgery. Ann Allergy Asthma Immunol. 2010;104:326-330.

28. Reddy RC, Baptist AP, Fan Z, Carlin AM, Birkmeyer NJ. The effects of bariatric surgery on asthma severity. Obes Surg. 2011;21:200-206.

29. Sultan S, Parikh M, Kurian M, Fielding G, Ren C. Early US outcome after laparoscopic adjustable banding in patients with a body mass index less than $35 \mathrm{~kg} / \mathrm{m}^{2}$. Surg Endosc. 2009;23:1569-1573.

30. Ahroni JH, Montgomery KF, Watkins BM. Laparoscopic adjustable gastric banding: weight loss, co-morbidities, medication usage and quality of life at one year. Obes Surg. 2005;15:641-647.

31. De Marco R, Locatelli F,Cerveri I, Bugiani A, Giammanco G. Incidence and remission of asthma: a retrospective study of the natural history of asthma in Italy. J Allergy Clin Immunol. 2002;110:228-235.

32. Chinn S. Obesity and asthma: evidence for and against a causal relation. J Asthma. 2003;40:1-16.

33. Shore SA. Obesity and asthma: implications for treatment. Curr Opin Pulm Med. 2007;13:56-62. 
34. Scott HA, Gibson PG, Garg ML, Wood LG. Airway inflammation is augmented by obesity and fatty acids in asthma. Eur Respir J. 2011;38:594-602.

35. Deesomchok A, Fisher T, Webb KA, et al. Effects of obesity on perceptual and mechanical response to bronchoconstriction in asthma. Am J Respir Crit Care Med. 2010;181:125-133.
36. Lessard A, Turcotte H, Cormier Y, Boulet LP. Obesity and asthma: a specific phenotype? Chest. 2008;134:317-323.

37. Juniper EF, Buist AS, Cox FM, Ferrie PJ, King DR. Validation of a standardized version of the Asthma Quality of Life Questionnaire. Chest. 1999;115:1265-1270.

\section{Publish your work in this journal}

The Journal of Asthma and Allergy is an international, peer-reviewed open-access journal publishing original research, reports, editorials and commentaries on the following topics: Asthma; Pulmonary physiology; Asthma related clinical health; Clinical immunology and the immunological basis of disease; Pharmacological interventions and new therapies. Issues of patient safety and quality of care will also be considered. The manuscript management system is completely online and includes a very quick and fair peer-review system, which is all easy to use. Visit http://www.dovepress.com/testimonials.php to read real quotes from published authors.

Submit your manuscript here: http://www.dovepress.com/journal-of-asthma-and-allergy-journal 